\title{
Bioeconomy in Arctic regions of Russia: problems and prospects
}

\author{
Anton Shcherbak ${ }^{1 *}$, Sergey Tishkov ${ }^{1}$,Valentina Karginova-Gubinova ${ }^{1}$ \\ ${ }^{1}$ Institute of Economics of the Karelian Research Centre of the RAS, 185030, Petrozavodsk, 50 Al. \\ Nevsky Prospect, Russia
}

\begin{abstract}
The article is dedicated to the relevant issue of rural and coastal communities in Arctic Russia and Nordics development. As a result of the modern development of society, rural areas have undergone significant changes. People are leaving rural areas due to a lack of education and vocational training opportunities, unemployment, and limited social contact. Recognition of the importance of depopulation of the rural area has required all countries to look at their strategy of development in a new way. The article identifies the main directions for the development of the rural area in Arctic regions. The authors proposed measures on how to increase the attractiveness of living in rural areas by economic measures. The article identifies the main directions for the development of these territories - the bioeconomy.
\end{abstract}

\section{Introduction}

Rural and coastal communities in the Arctic Russia and Nordics share many common challenges, such as demographic change, low diversification of economic activities, poor accessibility of services, goods and social life. More and more young people are leaving rural areas due to a lack of higher education and vocational training opportunities, unemployment, and limited social contact [1].

At the same time, the rural and coastal Nordic and Russian Arctic regions possess a wide variety of natural resources, and their sustainable utilization offers new opportunities for developing rural and coastal areas within the emerging bioeconomy. The Arctic region has unique opportunities for the development of specialized and niche products and services, based on renewable biological resources, due to its large areas of wilderness, unspoiled nature, specific climatic conditions, vast amounts of forest and marine resources, and providing opportunities for a multitude of uses.

In a broad interpretation, bioeconomy can be defined as an economy based on land and marine-based natural resources, including biowaste. It produces vital goods and services. In addition to bio-based raw materials, products and energy, bioeconomy also provides drinking water, fresh air and a range of other ecosystem services, including climate change mitigation (e.g. carbon sequestration in vegetation and soils), as well as adaptation (e.g. maintaining biodiversity) possibilities. Bioresources can also replace many goods and

\footnotetext{
Corresponding author: $\underline{\text { scherbaka@mail.ru }}$
} 
services that are currently produced using fossil-fuels and other non-renewable resources. These include a range of biofuels, bioplastics, and biopharmaceuticals (SNR 2018).

In this way, moving from fossil fuel to a bio-based economy, can contribute both to the fight against climate change, but also to new economic activity in and around rural regions. Bioeconomy does not only refer to the economic activities but also to the transformation process of the society as a whole, into becoming more sustainable, by promoting e.g. changes in consumption and production patterns, and enhancing the circularity of the use of the waste streams [2].

\section{Materials}

In addition to traditional forestry, blue bioeconomy and agriculture, also non-timber forest products (NTFPs), renewable bioenergy, wood construction, tourism, recreation, and green care potential of the Arctic are in growing demand, adding new opportunities for the development of the area. These blue and green bioresources are both located and dispersed in rural areas, giving unique opportunities for local economic development through local value-added, thereby contributing to job creation and leading to new economic activities in and around rural regions if the ownership of bioresources and user rights is established in the right way.

The transition from a fossil-fuel to a bioeconomy can generate significant technical and institutional innovation [3]. Bioresources are mostly located in rural and coastal areas and their productivity and accessibility differ between localities, given the variation in natural conditions and the management of ownership and use.

In the end, the bioeconomy business potential in all Arctic regions is significant but mostly underutilized at the moment. Based on the Finnish experiences, which arguably apply to other regions as well, the reasons for this are diverse.

Firstly, various bioeconomy lines of businesses are usually separated, and there is no cooperation or attempts towards a holistic approach in terms of their further development. This, in turn, hinders innovations because new ideas emerge often from the interfaces of different business domains. For example, traditional forestry and agriculture would benefit from adopting NTFPs and other means of diversification in their production and business portfolios.

Secondly, companies and entrepreneurs in the bioeconomy face challenges in their business development. In general, there is a lack of e.g. lobbying strength in promoting their interests. Another issue is getting funding and capital for investments. These reflect difficulties in cooperation between bioeconomy actors.

Thirdly, based on a survey of professionals, the biggest obstacles of starting new biobusinesses are the difficulties in networking and marketing (42\%), lack of funding (29\%), and obstacles posed by current legislation (29\%). From the point of bio-business employment, the biggest potential is offered by those companies which aim at increasing their international exports. To be successful in this, legislative issues can not be omitted whether considering domestic laws and regulations in and between the four partner countries, or when looking at trade laws and regulations in the global context.

Fourthly, the availability of a well-trained workforce with the necessary knowledge and skills, from academia, industry or the primary-production sector, across public and private sectors, and encompassing different skill levels are among the key prerequisites for developing a bioeconomy. A mismatch between the needs for competencies and skills of the bioeconomy-related businesses and educational and training opportunities available in the region is a significant challenge, especially for rural and remote areas.

When aiming at utilizing the full potential of bioeconomy in Arctic regions, youth in general and students in vocational colleges and universities, in particular, are the key actors. 
Not only do regions survive or wither with the youth population staying or leaving, but so do the existing and future bioeconomy companies and entrepreneurs as well. New workforce and new entrepreneurs originate from educated young people, willing to stay and work in their home region and as part of their surrounding communities.

Another viewpoint of the success of Arctic regions in economic and social terms, is the fact that cooperation and networking are essential for everyone in the future. We should increase pooling and co-developing our scarce resources - whether human, capital, educational or business know-how based - to be able to compete with opportunities, provided to our youth and students from outside our regions.

Finally, bioeconomy resources and potentials should be taken under scrutiny by developing the somewhat vital triangle of bioeconomy actors operating in rural areas: young professionals, students and educational institutions, companies and entrepreneurs, and business service providers in regions. Together they can alleviate the problems found in rural areas in general, but in particular, they can resolve problems stemming from the lack of cooperation, marketing, and e.g. business funding.

\section{Results}

If we look at the Russian economy at the turn of the beginning of the 1990s, we can see that certain branches of bioeconomics have already been actively developing since Soviet times. During this time period, several branches of bioeconomics have developed, including agriculture and the timber industry in several regions.

In the Republic of Karelia, bioeconomics is focused immediately in several areas. First is the timber industry that is historically well-developed industry in the region.-This industry, at different time periods, occupied up to $1 / 3$ of the entire industry of the region. Second is energy industry. A large amount of energy is generated from renewable energy sources, so in the region up to $50 \%$ of the generated electric energy is generated at hydroelectric power plants of different capacities. Third is the fishing industry, which is represented not only by industrial fisheries but also by industrial fish farming (mainly trout farming). As of today, $70 \%$ of the trout market in Russia is grown in Karelia.

At the turn of the 2000 s, over 500 enterprises with various ownership forms functioned in the timber industry in the Republic of Karelia, which amounted to about $35 \%$ of the entire industrial sector as a whole [4].It should be noted that this industry was represented by enterprises engaged not only in wood harvesting and processing, but also in the pulp and paper industry. Over the past decade, the industry has undergone significant changes in the direction of increasing deep processing. In addition to the usual areas for the production of lumber and products from them, the processing of wood waste into fuel granules or pellets has appeared and is actively developing.

This type of product primarily remains in demand abroad and most of the pellets produced are delivered to foreign markets. The production of this type of product is primarily associated with its demand on world markets. The pellet market is showing steady growth. So in 2010, total world consumption was 5 million tons per year, in 2018 it already amounted to 23 million tons, and in 2025, the annual consumption will be 52 million tons [5]. Moreover, in Russia, only the North-West district accounts for up to $50 \%$ of the total pellet production. The Republic of Karelia is not only a supplier of wood raw materials to other regions, but actively produces them itself.

In the field of commercial fish farming of agricultural industry, there is an active development, for instance, in Karelia.

From 1993 to 2018, the volume of cultivation of commercial trout and the production of planting stock increased 80 times and, according to the results of 2018, amounted to 27.2 thousand tons per year. Moreover, as part of the implementation of the socio-economic 
development of the Republic of Karelia until 2020, the Government of Karelia, together with the Ministry of Agriculture and Fisheries of the Republic of Karelia, approved new goals for the development of commercial fish farming. So, according to the approved plans, the industry should reach the following indicators: at least 30 thousand tons by 2020 and 35 thousand tons in 2025. At the same time, today the volume of issued permits for industrial fish farming in the inland waters of Karelia exceeds 50 thousand tons. Taking into consideration the use of the White Sea and closed water supply facilities, the total volume of farmed fish per year may reach 100 thousand tons. Along with commercial fish farming, processing of fish products, the cultivation of planting material, and the production of feed for fish are developing.

One of the important components of bioeconomics is the energy sector. In countries with the most developed economies, the focus is on renewable energy, given the fact that most regions are highly dependent on primary energy supplies from outside their regions. This indicates the low security of the energy system due to its sources. In addition, the high deterioration of energy networks threatens the energy and economic security of individual regions and the state as a whole. To increase the security level of regional energy security, it is necessary to reconstruct existing and build new modern energy networks. It is also required to reduce the dependence of regional energy systems on external supplies of energy carriers. This can be done by introducing local energy resources into energy turnover, including from renewable sources.

Despite the great potential for the use of renewable energy, its share in the total energy balance is less than $2 \%$. At the same time, due to the socio-economic, geographical, and climatic specifics, the regions differ from each other in the volume and technology of energy used from renewable sources. In some regions, the share of generated electricity using hydropower is significant, as in the Republic of Karelia this indicator reaches $70 \%$ of all generated electricity in the region [6].

In some cases, for peripheral regions, including northern ones, with poorly developed energy networks, a decentralized energy supply system should be used. Its significant advantage is that a decentralized system of supplying end consumers with energy resources can be installed and put into operation as soon as possible in any place, regardless of the distance from the centralized power supply networks.

One of the features of decentralized energy supply is that in the local generation (conversion) of energy, great importance is given to non-fuel energy and energy based on renewable energy sources inherent in this territory. The advantage of renewable energy is already highly appreciated in the EU, China, USA, and others, in which state programs for the development of renewable energy and the transfer of buildings to "conditionally passive" and "passive" levels with an annual energy consumption of 10-30 kWh / m2. At the same time, a decrease in specific energy consumption allows reducing costs for providing facilities with the necessary energy infrastructure. This is especially important for the northern peripheral territories as fuel delivery and energy supply organization are characterized by high costs, primarily associated with a considerable distance from the main energy lines and centers. Low specific energy consumption makes it possible to almost completely cover the end-user demand for energy resources from renewable energy sources.

Thus, the main factors for the development of renewable energy are the following: the depletion of traditional sources of fossil fuels, while their production is associated with an increase in the cost of their production; a significant negative impact on the environment from fossil energy sources. As a result, these two factors lead to higher energy prices based on traditional energy. For the final consumer, this is expressed in the annual increase in the tariff for energy resources by an average of $15-25 \%$. At the same time, the cost of renewable energy equipment is reduced. In some cases, the application of a particular 
technology for the conversion of renewable energy is more economically feasible, in comparison with traditional energy based on fossil energy sources [7]. For example, in the United States, as of 2013, the cost of solar energy was 0.056 US dollars per kilowatt-hour, and wind energy was 0.014 US dollars. At the same time, the cost of kilowatt-hours of energy from gas and coal costs 0.061 and 0.066 , respectively.

Given the peculiarity of the northern peripheral regions, the most promising sources of renewable energy at the moment are biomass energy, low-potential energy of the earth, wind, and water, as well as the sun.

Biomass. Biomass can be used as fuel in local boiler houses. Peat and woodworking waste are most often used as biofuels. In Finland, for example, up to $26 \%$ of energy consumption is covered by debris and wood waste located in Russian regions. Russia has a huge potential for biogas production. This primarily applies to enterprises in the field of agriculture. The raw material for the production of a renewable energy source is biogas. It can be plant crops and biological waste: manure, slaughterhouse waste, plant waste, sewage, fats, biomass, food industry waste, garden waste, and malt sludge. In Russia, there is a small number of agricultural enterprises (livestock complexes, poultry farms, fur farms, as well as plant water resources), which can fully provide themselves with heat and electricity through their biogas. Modern technologies allow the use of biogas as a final product for gas production or conversion into heat and electricity [8].

Biogas production technologies are especially suitable for use in water treatment plants in large cities and towns.

Sewer drains. This technology will allow you to earn extra profit, and give you the ability to fully satisfy your needs for electricity and heat.

Biogas production pays off in landfills. On-site landfills can organize the production of methane. This will fulfill several functions: processing household waste, generating new energy resources, reducing greenhouse gas emissions, and improving the environment. Such landfills are common in most countries, including the United States, China, Japan, the Netherlands, Belgium, and many others. For example, in the circumpolar city of Oulu (Finland), the OivaRoina household waste landfill was reconstructed and now is not only a waste processing company, but also a gas producer and an electric power generator. Gas is pumped out using special pumps and a piping system, laid in the thickness of household waste. The landfill has its power plant with a capacity of $200 \mathrm{kWh}$. It is represented by four gas electric generators operating on methane with an installed capacity of $50 \mathrm{kWh}$ each. This capacity is enough to meet all the energy needs of the enterprise. The landfill sells surplus gas to nearby enterprises. This technology, for the utilization and conversion of household waste, has worked well and could be a good example for Russian landfills with domestic waste since the problem of recycling household waste is currently very acute in most large settlements in Russia.

Heat pumps. It is one of the promising technologies that have not yet been applied in Russia. The technology of using the "heat pump", in comparison with wind and solar energy, is not affected by weather conditions. It is based on the selection of low-grade heat from the environment (earth, water or air). In terms of its efficiency, it significantly surpasses other technologies for generating thermal energy in the absence of an extensive network of gas pipelines in the northern peripheral regions, while in terms of its performance, the cost of a unit of thermal energy is lower than that of a gas boiler operating on natural gas.

The technology of using the "heat pump", in comparison with wind and solar energy, is not affected by weather conditions. It is based on the selection of low-grade heat from the environment (earth, water or air). The greatest efficiency is achieved when using water as a source of this heat. This is because water has one of the largest indicators of specific heat. Placing the evaporator in a pond will significantly reduce the initial cost of building heat 
pumps, which is especially advisable in areas with large reserves of water resources. Heat pumps can be small, designed for the needs of a separate house, and large, which are able to satisfy the needs for heating and hot water of entire areas. One of the largest heat pumps is the KatriVala project in Finland, in the city of Helsinki, with a total capacity of $90 \mathrm{MW}$ of thermal energy and $60 \mathrm{MW}$ of cold. In the last decade, this technology has become especially widespread. Today, about 3 million units are operated in Japan; in Sweden, about 500,000 homes are heated by various types of heat pumps.

Wind. The potential use of wind energy in Russia is estimated as significant. Even though wind energy in Russia is not evenly distributed, part of the territories where there is no centralized energy supply has significant wind energy resources. Kamchatka, Chukotka, Sakhalin, Yakutia, along the coast of the Arctic Ocean, the Gulf of Finland, as well as the Black and Caspian Seas have high average annual wind speeds.

The rational use of the distributed wind potential allows it to be used both in stand-alone wind power installations and when using wind turbines as part of local energy systems. Russia's gross wind potential is estimated at $80 * 10^{15} \mathrm{kWh} /$ year, economic $-40 * 10^{9}$ $\mathrm{kWh} /$ year.

In Soviet times, several of projects for the construction of wind farms were developed, but were never implemented. (For example, on the White Sea coast (near the village of Rabocheostrovsk) with a total capacity of $18 \mathrm{MW}$ ). In addition to large installations, their capacity exceeds $7 \mathrm{MW}$; there are medium and low power windmills. Such installations will be in demand among individuals and small enterprises. First of all, wind energy must be mastered and used on islands and in remote and inaccessible areas where there is no central energy supply.

Hydropower. Russia is one of the most water-supply countries in the world. The total length of Russian rivers exceeds 8 million $\mathrm{km}$ (while $90 \%$ of the rivers are less than $100 \mathrm{~km}$ long). There are more than 2.5 million rivers total in Russia and the economic potential of small and ultra-small hydropower plants is used by about $0.5 \%$ [9].

Under Russian conditions, the use of energy, from small watercourses, is one of the most effective directions in the development of renewable energy sources. One of the real possibilities is to solve the problem of power supply to remote energy-deficient regions, which occupy up to $40 \%$ of its territory, where there are no distribution power lines, and where organic fuel is associated with great temporary, technical and financial difficulties.

The technical potential of all Russian rivers is 382 billion $\mathrm{kWh}$. Consumers use only $0.5-0.6 \%$ of this potential. Moreover, $44 \%$ of the city's population and $90 \%$ of the rural population now live on the territory of small river basins. The gross potential of small rivers in the North-West Region is 81.6 billion $\mathrm{kWh}$, the technical potential is 31 billion $\mathrm{kWh}$, of which economic is $24.1 \%$. According to the Water-Energy Cadaster, 5160 small rivers are registered only in the territory of Karelia. The number of unaccounted rivers reaches 13.5 thousand. Of the 34 mothballed small hydropower plants in the Leningrad Region, a third can be reanimated and launched. This will allow generating at least 24 billion $\mathrm{kWh}$ of electricity annually. The sources of small hydropower plants include both artificial and natural watercourses: streams, small and medium rivers with a length of up to $100 \mathrm{~km}$ and a catchment area of up to $2000 \mathrm{~km}$, irrigation and shipping channels, as well as spillways of reservoirs, artificial ponds, locks and hydraulic systems on technological pipelines, etc. It is believed that small hydropower plants are the optimal solution for the autonomous energy supply of villages, farms, holiday villages, and farms. The Republic of Karelia is actively developing the hydropower potential on its territory. About $70 \%$ of the region's electricity generation is produced from its hydropower plants. The construction of new hydroelectric power stations has already been planned in the region: a cascade on the Chika-Kem River, the Vodlinsky Cascade, and a small hydroelectric station on the Segezha and Vyg rivers. The implementation of these projects will increase the energy supply of Karelia, reduce the 
region's dependence on electricity supplies, and give a development of the territory and additional jobs.

Solar. Many are skeptical of solar energy, explaining this by the small number of sunny days. Nevertheless, for most territories, the use of solar power plants is economically feasible. First of all, it is converting solar radiation into heat. It can be completely different installations from the most elementary (black barrel with water on the roof) to more complex ones (glass vacuum tubes).

Since the late 90s, the construction of houses with a "solar" architecture has spread throughout the world, which allows reducing the energy consumption of the house and maximizing the use of solar energy. Installations of various designs for heating water and air (solar collectors) were also used. They are used not only in the southern latitudes, but also in the north (Finland, Sweden, Canada, etc.). In all cases, solar heating panels were used as an additional source of heat; however, they significantly reduce heating costs to several thousand $\mathrm{kWh}$ per year.

The generation of electricity based on solar energy has also gained distribution not only in the southern territories, but also in the northern latitudes. The joint use of solar energy with diesel generators allows us to obtain significant fuel savings, while reducing emissions of combustion products into the atmosphere.

Solar energy must be actively involved in the overall energy balance. The use of combined heating and hot water systems in some cases makes it possible to recover up to $50 \%$ of the energy. The task consists of the correct energy calculation and selection of appropriate equipment. In some cases, the development of new or partial modernization of existing equipment is required. Given the climatic parameters and the level of insolation, you can choose a comprehensive energy supply system that will use the energy of the sun as the main energy source. For northern regions with a moderate level of solar insolation, an auxiliary heat source will also be required, which can be represented by standard boiler equipment, that works in parallel with the solar collector and is connected to a heat accumulator. Boiler equipment can run on any fuel, which may include coal, firewood, wood chips, gas, diesel fuel, and others.

The key unit of such a system is a thermal battery. Increasingly, the thermal energy storage system is being laid at the design stage of the building. In these cases, it is possible to use very large heat accumulators that are integrated into the elements of the house. Due to the large volume of the heat accumulator, it is possible not to use boiler equipment for weeks and cover the building's needs only using the energy stored in the heat accumulator. Moreover, a system of solar collectors and control equipment will constantly recharge it [10].

The construction of similar systems has already spread in Europe, including the countries of Northern Europe. For example, one company in Finland, Kaukora OY, based on this approach, developed a technical solution for heating a building and hot water, using solar energy.

The developed JASPI system consists of a heat accumulator, a system of solar collectors, boiler equipment running on diesel fuel and gas, and also a control system. With a minimum volume of heat accumulator of 750 liters, the system requires energy costs of $30-40 \%$ per year [11]. The important factor is that Finland is a northern country and has a moderate level of solar insolation, which corresponds to the order of $1 \mathrm{MW} * \mathrm{~h}$ per $1 \mathrm{~m} 2$ of surface per year.

As for the RES sector, the most promising sources in this direction for the Republic of Karelia is energy biomass, and low potential energy of the earth, wind, and sun energy.

In Karelia, a part of boiler houses is being actively converted for local fuels such as peat and woodworking waste. It is positive affecting the efficiency of energy production. Since fuel oil prices are rising in Russia every year, therefore, the use of wood waste for heat 
production could be competitive. Thus, forest resources in the northern regions of Russia (this is especially true for the Republic of Karelia and the Arkhangelsk region) can be used to produce renewable fuels, such as wood chips and pellets. In all areas of Karelia, boiler equipment is being gradually modernized, during which the boiler is converted to local fuels. Several of boiler houses in the region were converted to local types of fuel wood chips and peat: Suojärvi, pos. Porosozero, pos. Essoila, pos. Harlu, pos. Veshkelitsa and many others.

The next direction in RES of Karelia is biogas production. This primarily applies to enterprise of Agriculture. Raw materials for the production of renewable energy sources of biogas can be plant crops and biological waste: manure, slaughterhouse waste, plant waste, sewer effluents, fats, biomass, food industry waste, garden waste, malt sludge, etc.

Wind energy in Karelia is unevenly distributed. The greatest potential for wind generation is the coast of large lakes and seas. In the Republic of Karelia, there are two of the largest lakes in the world - Ladoga and Onega, as well as the White Sea. According to expert estimates, the wind potential in Karelia is 10,000 GW per year.

The total hydropower potential in the North-West Federal District is estimated at 15 billion $\mathrm{kWh}$. The Republic of Karelia is actively using the hydropower potential. Currently, in the region, there are 19 small hydroelectric power stations, where about $70 \%$ of the total generated electric energy of the region is produced. Also, there is a construction of several more hydropower plants with total capacity of more than $150 \mathrm{MW}[12,13]$.

\section{Conclusion}

It is obvious that without the use of modern green technologies that can solve many social, economic, and environmental problems it is impossible to ensure the innovative development of the economy and improve the health status of the population. Given the huge potential in the field of bioeconomics in Russia, it is necessary to actively involve green technologies in the economy. This will contribute to improving the environmental situation in the regions and thereby will improve the quality and life expectancy of the population.

Most regions are characterized by low security of the energy system at the expense of their sources, high dependence on the supply of primary energy resources from outside of their regions, and high deterioration of energy networks. All this negatively affects the development of the territory and jeopardizes the energy and economic security of individual regions and the state as a whole. In this regard, it is difficult to overestimate the importance of renewable energy for energy security. As energy-based on renewable sources, it can, first of all, reduce the dependence of regional energy systems on external energy supply and, second of all, ensure diversification of the energy system. Identification of priority areas and activities for developing the potential for using local types of renewable energy, development, and implementation of targeted programs will contribute to the development of the territory. Bioeconomics is a global phenomenon and wears an international character. However, biomass is a necessary element to build similar economies. It cannot be easily and cheaply transported over long distances. Due to this, it is important to build a local infrastructure, a tour that would allow local factories and enterprises the most efficient way to ensure the use and recycling of waste and biological materials [14, 15].

The Karelian authorities, in the development of the region, have already relied on individual elements of bioeconomics: the timber industry and agriculture, as one of the promising sectors of the region's economy. The key to the development of bioeconomics is to increase the investment in research and sponsorship of the research in this area.

The reported research was funded by Russian Foundation for Basic Research and the government of the Republic of Karelia of the Russian Federation, grant № 18-410-100002. 


\section{References}

1. A. Karlsdóttir, A. Cuadrado, Nordregio Policy Brief, 5 (2018)

2. I. Grundel, M. Dahlström, CRS_Policy Brief, 1 (2015)

3. J. Bryden, S. Gezelius, K. Refsgaard, J. Sutz Innov. Develop.7, 1-16 (2017)

4. E. Nemkovich, A Kozlov Forest complex of the Republic of Karelia (2006)

5. Global demand for pellets: forecasts at the end of 2018, https://albnn.com/production/articles/mirovoy-spros-na-pellety-prognozy-v-kontse-2018goda/

6. S. Tishkov, A. Shcherbak, Trend. Manag. 2, 11-18 (2019), DOI: 10.7256/24540730.2019.2.29408)

7. A. Shcherbak, Probl. Mod. Sci. Educ. 8, 31-33 (2019), DOI: 10.24411/2304-23382019-10801)

8. I. Deviatkin, J. Havukainen, M. Horttanainen, M. Manttari, Was. Manag. 90, 132140, (2019), DOI: 10.1016/j.wasman.2019.04.031)

9. Hydropower potential of small rivers, Bellona, http://bellona.ru/2008/06/06/gidroenergeticheskj-potentsial-maly (2006)

10. Solar heating, URL: https://jaspi.fi.

11. A. Shcherbak, S. Tishkov, V. Karginova-Gubinova, Industrial power engineering (to be published)

12. L. Ryden, Rur. Develop. Land Use, 186-195 (2012)

13. S. Tishkov, A. Shcherbak, V. Karginova-Gubinova, A. Pakhomova, V. Alhanaqtah, Manag. Theor. Stud. Rur. Bus. Infrastr. Develop. 41-1, 33-42 (2019) (DOI: 10.15544/mts.2019.04)

14. K. McCormick, N. Kautto, Sustainability, 5, 2589-2608 (2013) 